\title{
Neoadjuvant immunotherapy in breast cancer: a paradigm shift?
}

\author{
Elena Fountzila ${ }^{1,2}$ and Michail Ignatiadis ${ }^{3}$ \\ ${ }^{1}$ European University Cyprus, German Oncology Center, Agios Athanasios, 22006, Cyprus \\ ${ }^{2}$ Second Department of Medical Oncology, Euromedica General Clinic, Thessaloniki, 54645, Greece \\ ${ }^{3}$ Department of Medical Oncology \& Academic Trials Promoting Team, Institut Jules Bordet, Université Libre de Bruxelles, Bruxelles, 1000, Belgium
}

\begin{abstract}
Despite advances in clinical management, a proportion of patients with early-stage triplenegative breast cancer (TNBC) recur after local treatment. The concept of neoadjuvant systemic therapy has been widely adopted to improve clinical outcomes of patients with TNBC and other breast tumour types. Recently, promising data were reported from the first prospective phase III, randomised trial assessing neoadjuvant chemotherapy combined with the programmed cell death protein 1 (PD-1) inhibitor pembrolizumab versus placebo in patients with early-stage TNBC. The addition of pembrolizumab resulted in a significant increase in pathologic complete response (pCR) rates. Similarly, in the IMpassion031 trial, the use of atezolizumab in combination with neoadjuvant chemotherapy in patients with early-stage TNBC led to improved $\mathrm{pCR}$ rates compared to placebo, regardless of programmed death ligand 1 (PD-L1) expression. Ongoing trials are testing other PD-1/PD-L1 inhibitors in combination with neoadjuvant chemotherapy in TNBC and other tumour subtypes. However, not all patients benefit from the addition of immunotherapy, while a proportion of patients experiences serious adverse events. It is critical to identify predictive biomarkers of response, to accurately select patients who will benefit from immunotherapy, thus sparing the rest from ineffective treatments with unnecessary toxicity and treatment costs. In this review, we summarise the literature on reported and ongoing neoadjuvant clinical trials evaluating immunotherapy in breast cancer.
\end{abstract}

Keywords: biomarker, clinical trial, immunotherapy, neoadjuvant, pathologic complete response, triple-negative breast cancer

\section{Introduction}

Despite advances in clinical management, a proportion of patients with early-stage breast cancer recur after local treatment. Recurrence rates are higher in HER2-positive or triplenegative disease, and prognosis of patients with advanced cancer remains poor [1, 2]. Thus, there is an unmet need to improve therapeutic management of early-stage disease to decrease the likelihood of recurrence. Adjuvant chemotherapy with standard regimens, including anthracyclines, taxanes and cyclophosphamide was the preferred therapeutic option for patients with operable breast cancer. Recently, the concept of pre-operative
Correspondence to: Michail Ignatiadis Email: Michail.ignatiadis@bordet.be

ecancer 2020, 14:1147

https://doi.org/10.3332/ecancer.2020.1147

Published: 03/12/2020

Received: 31/03/2020

Publication costs for this article were supported by ecancer (UK Charity number 1176307).

Copyright: ( $)$ the authors; licensee ecancermedicalscience. This is an Open Access article distributed under the terms of the Creative Commons Attribution License (http:// creativecommons.org/licenses/by/3.0), which permits unrestricted use, distribution, and reproduction in any medium, provided the original work is properly cited. 
(neoadjuvant) systemic therapy has been increasingly used to improve the clinical management of patients with breast cancer. First, the use of neoadjuvant therapy may lead to a significant decrease in the tumour and/or lymph node load and facilitate the subsequent surgical procedures [3, 4]. In addition, this approach provides informative data regarding prognosis and response to systemic interventions. Pathologic complete response $(\mathrm{pCR})$ in the breast and axillary nodes noted at the time of surgery following neoadjuvant treatment has been associated with improved clinical outcomes, particularly in triple-negative and HER2-positive diseases [5-9]. Thus, it has been accepted by the U.S. Food and Drug Administration as a surrogate endpoint to accelerate drug approval [10]. Finally, based on recently published data, the addition of chemotherapeutic agents as adjuvant treatment in patients with breast cancer who did not achieve pCR after neoadjuvant therapy should be considered [11, 12]. Various therapeutic agents are currently being evaluated in the neoadjuvant setting [13-16].

In the evolving era of immunotherapy, several clinical trials are focusing on the evaluation of immunotherapeutic agents at the neoadjuvant setting in patients with triple-negative breast cancer (TNBC) [17-21]. These attempts are supported by promising data on the use of immunotherapy in patients with advanced triple-negative disease. In a recently published phase III trial, the administration of the programmed death-ligand 1 (PD-L1) inhibitor atezolizumab in combination with chemotherapy led to improved progression-free survival (PFS) compared to chemotherapy alone as first-line treatment in patients with metastatic TNBC [22]. The rationale of using neoadjuvant immunotherapy lies, among others, on the potential increase of systemic immunity that would improve the clinical response of the primary tumour and eradicate residual micrometastatic disease [23]. Pre-clinical work suggests that neoadjuvant depletion of regulatory T cells (Treg) in mice led to a lack of observable lung micrometastases [24]. Compared to mice that received adjuvant Treg depletion, mice with neoadjuvant treatment had improved overall survival. In the clinical setting, the administration of two pre-operative doses of a PD-1 inhibitor in patients with resectable non-small cell lung cancer led to an increased number of T-cell clones in the tumour and peripheral blood [25]. Similarly, in the OpACIN trial, where patients with palpable stage III melanoma were randomised to receive adjuvant (four courses after surgery) or neoadjuvant (two courses before and two after surgery) treatment with ipilimumab and nivolumab [26], investigators reported higher rates of tumour-resident T-cell clones in the peripheral blood of patients who received neoadjuvant compared to patients who received adjuvant immunotherapy. In the updated outcome analysis, the 3-year relapse-free survival and OS rates were $80 \%$ and $90 \%$ for the neoadjuvant arm and $60 \%$ and $67 \%$ for the adjuvant arm, respectively. The study was not powered to assess differences between arms [27].

Chemotherapy agents are evaluated to identify the best partner to be combined with immunotherapy, using different administration schemes, including induction chemotherapy followed by immunotherapy or induction immunotherapy followed by a combination of chemotherapy and immunotherapy. In metastatic TNBC, the addition of atezolizumab to nab-paclitaxel [22] but not to paclitaxel [28] improved the PFS in metastatic TNBC suggesting that the chemotherapy partner might be important for the efficacy of atezolizumab. There are pre-clinical data suggesting synergistic effects between specific chemotherapeutic agents and immunotherapy including stimulation of anti-tumour immune responses by chemotherapy [29-35]. These data support the upregulation of immune-related genes, increased T-cell infiltration and T-cell receptor diversity, recruitment of functional dendritic cell-like antigen-presenting cells into the tumour bed and enhancement of the efficacy of immunotherapy.

In this article, we review the literature on neoadjuvant clinical trials evaluating immunotherapy in breast cancer. We discuss the main findings of the reported studies and the need for biomarker discovery to individualise treatment selection (Tables 1 and 2). Ongoing clinical trials are reported as well.

\section{Neoadjuvant immunotherapy trials in early-stage breast cancer}

\section{Efficacy}

One of the first trials evaluating neoadjuvant treatment with immunotherapeutic agents was the I-SPY 2 trial (Investigation of Serial Studies to Predict Your Therapeutic Response With Imaging and Molecular Analysis 2), a multi-centre, phase 2, randomised clinical trial [17]. Based on the adaptive design, therapeutic agents that would not prove to be efficacious would be dropped from the study, while others showing clinical benefit would quickly move forward to phase III clinical trials. In multiple concurrently enrolling therapeutic arms, the efficacy of novel drugs in combination with standard neoadjuvant chemotherapy was compared to standard treatment alone. One of the arms evaluated the benefit from the addition of the programmed cell death protein 1 (PD-1) inhibitor, pembrolizumab to weekly paclitaxel (for 12 
weeks) followed by four cycles of doxorubicin and cyclophosphamide every 3 weeks, in patients with TNBC or hormone-receptor-positive, HER2-negative, early-stage breast cancer. Sixty-nine patients were randomised to receive pembrolizumab. The addition of pembrolizumab to standard neoadjuvant therapy resulted in increased $\mathrm{pCR}$ rates in patients with HER2-negative tumours (estimated pCR rates with pembrolizumab: $44 \%$, $95 \%$ probability interval: $33-55$ versus $17 \%$ without pembrolizumab, $95 \%$ probability interval: $11-23$ ) [17]. In patients with TNBC, there was a threefold increase in pCR rates with the addition of pembrolizumab $(22 \%$ without pembrolizumab versus $60 \%$ with pembrolizumab). The addition of pembrolizumab resulted in a similar improvement of pCR rates in hormone receptor-positive, HER2negative disease (30\%-13\%). The pCR rate was less-than-expected in the control arm of the trial (22\% in the TNBC subgroup), compared to previous studies reporting higher pCR rates ranging from $26 \%$ to $38 \%$ with standard chemotherapy [36, 37]. Therefore, the statistically significant increase of $\mathrm{pCR}$ rates with the addition of immunotherapy to standard treatment needs to be interpreted with caution. A newer investigational arm in the I-SPY 2 trial is evaluating the benefit from adding the combination of the PD-L1 inhibitor, durvalumab and the poly ADP ribose polymerase inhibitor, olaparib to standard neoadjuvant chemotherapy (NCT01042379).

Apart from I-SPY 2, pembrolizumab was evaluated in combination with chemotherapy at the neoadjuvant setting in other trials [18, 19]. KEYNOTE-173 was a multi-cohort phase $1 \mathrm{~b}$ study assessing different time and dosing schedules of six neoadjuvant chemotherapy regimens (paclitaxel, nab-paclitaxel, doxorubicin, cyclophosphamide and carboplatin) combined with pembrolizumab in patients with locally advanced TNBC (NCT02622074) [18]. Overall, the pCR rate was 60\% (90\% Cl: 30-85) [18]. Patients who had achieved pCR had 12-month event-free survival (EFS) rate of $100 \%$ compared to patients who had not (88\%).

Based on these preliminary promising data, the addition of pembrolizumab to neoadjuvant chemotherapy was prospectively evaluated in the KEYNOTE-522 phase III clinical trial [19]. This was the first prospective phase III, randomised, double-blind trial assessing neoadjuvant chemotherapy combined with pembrolizumab versus placebo, followed by adjuvant treatment with pembrolizumab/placebo in order to complete 1 year in patients with early-stage TNBC. The trial enrolled patients with a node-positive disease or with tumours $>2 \mathrm{~cm}$ irrespective of nodal status. Patients were stratified based on nodal status (positive or negative), tumour size (T1/T2 or T3/T4) and administration schedule of carboplatin (weekly or every-3-week). Chemotherapy comprised of four cycles of carboplatin and paclitaxel followed by four cycles of doxorubicin/epirubicin and cyclophosphamide. The primary endpoints of the study were pCR rates as assessed locally and EFS in the intention-to-treat population. At the first interim analysis including 602 patients, there was an impressive increase in pCR rates from $51.2 \%$ in the placebo-arm to $64.8 \%$ in pembrolizumab-arm $(p<0.001)$ [19]. The benefit from the addition of pembrolizumab to chemotherapy was maintained in all clinical subgroups. At a median follow-up of 15.5 months, $7.4 \%$ of patients who received pembrolizumab had recurred compared to $11.8 \%$ of patients who received placebo ( $\mathrm{HR}=0.63,95 \% \mathrm{Cl}: 0.43-0.93)$. Because statistical significance at the pre-specified p value boundary of 0.000051 was not reached, a longer follow-up is needed [19]. Long-term safety and efficacy data are eagerly awaited.

Two smaller neoadjuvant studies failed to demonstrate a statistically significant increase in pCR rates when the PD-L1 inhibitor durvalumab [20] and atezolizumab [21], respectively, were added to neoadjuvant chemotherapy. GeparNuevo was a prospective, randomised, doubleblind, placebo-controlled phase II trial that evaluated the improvement in $\mathrm{PCR}$ rates by the addition of durvalumab in neoadjuvant treatment of patients with non-metastatic breast cancer (NCT02685059) [20]. Patients received neoadjuvant chemotherapy with nab-paclitaxel followed by dose-dense epirubicin/cyclophosphamide concurrently with durvalumab versus placebo. Of the 235 patients screened, 174 patients received treatment. pCR was noted at $53 \%$ of patients who received durvalumab compared to $44 \%$ of patients who received placebo (unadjusted continuity corrected $p=0.287$ ). Intriguingly, there was a significant improvement in $\mathrm{pCR}$ rates in patients who received durvalumab two weeks before the start of chemotherapy (window-phase) compared to placebo ( $p C R$ rate $61 \%$ versus $41 \%, O R=2.22,95 \%$ $\mathrm{Cl} 1.06-4.64, p=0.035$; interaction $p=0.048$ ). However, currently, it cannot be concluded whether this difference is due to immunological priming or due to a chance subgroup analysis finding. This interesting observation needs further validation. Moreover, preliminary results from the phase III NeoTRIPaPDL1 Michelangelo study showed that the addition of atezolizumab to neoadjuvant treatment with carboplatin and nab-paclitaxel in patients with non-metastatic TNBC resulted in not significantly different pCR rates compared with chemotherapy alone (43.5\% versus 40.8\%, respectively) [21]. However, the study's primary endpoint was EFS at 5 years following randomization of the last patient. Differences in clinical outcomes between the GeparNuevo, the NeoTRIPaPDL1 Michelangelo and the Keynote-522 study [19, 21] might be related to different drugs (PD-L1 versus PD-1 inhibitors, respectively), different chemotherapy backbone regimens and differences in the trials' sample size. Ongoing phase III trials (NCT03281954, NCT03498716) will clarify the role of atezolizumab in early TNBC. Details on the efficacy and toxicity of the aforementioned schemes are depicted in Tables 1 and 2, respectively. 


\begin{tabular}{|c|c|c|c|c|}
\hline & 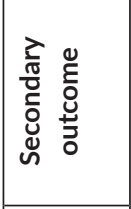 & 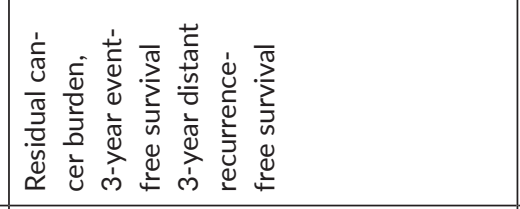 & 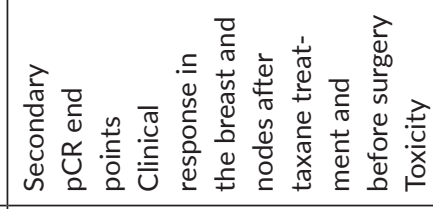 & 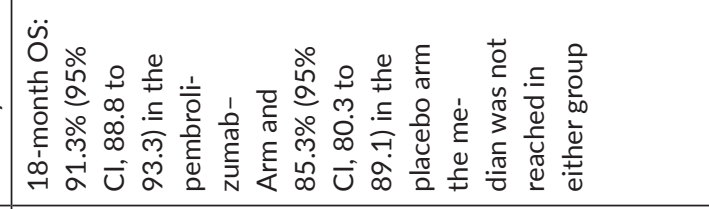 \\
\hline & 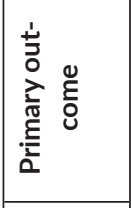 & 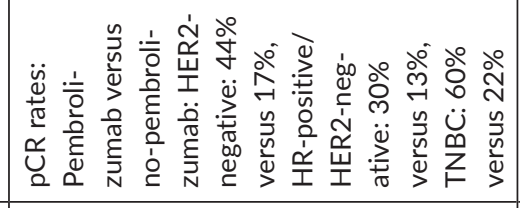 & 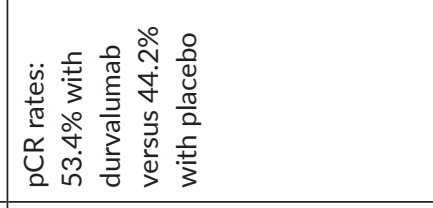 & 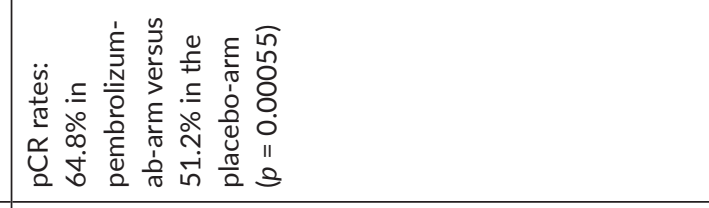 \\
\hline & 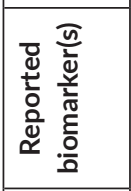 & $\begin{array}{l}\stackrel{\circ}{\underline{\underline{I}}} \\
\stackrel{\circ}{Z}\end{array}$ & 岁官 & 光 \\
\hline & 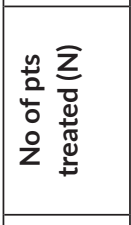 & 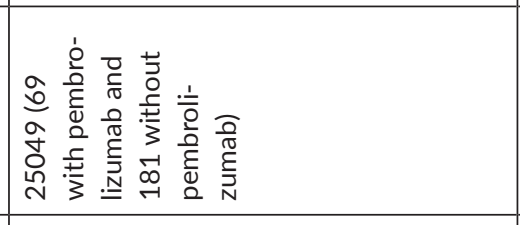 & $\underset{I}{ \pm}$ & 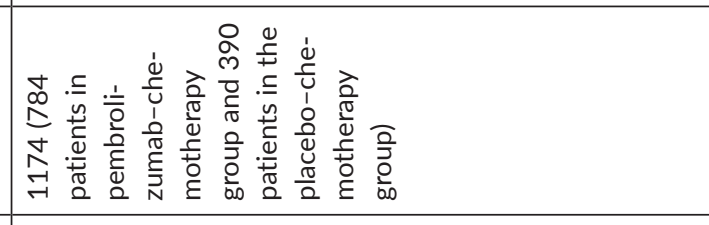 \\
\hline & 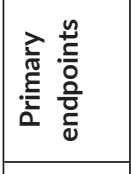 & 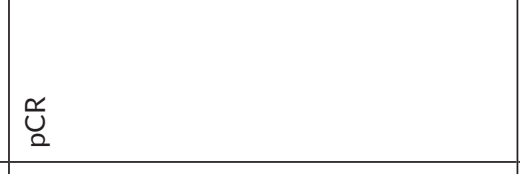 & \begin{tabular}{l} 
O̊ \\
\hdashline \\
\end{tabular} & 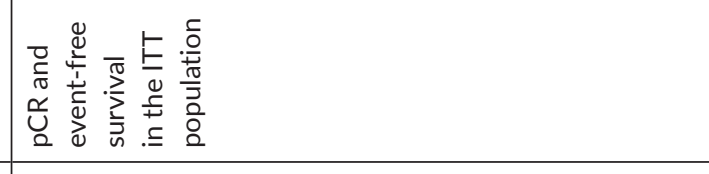 \\
\hline & 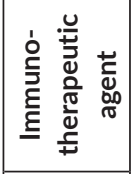 & 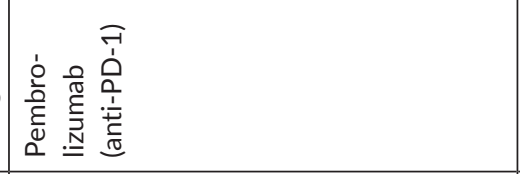 & 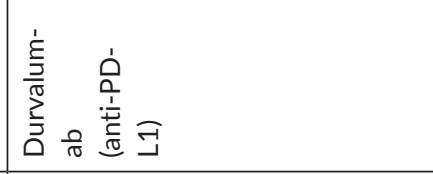 & 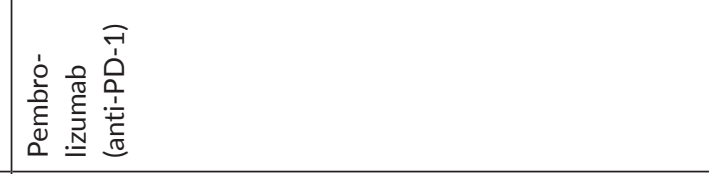 \\
\hline & 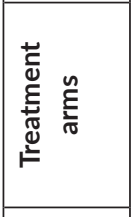 & 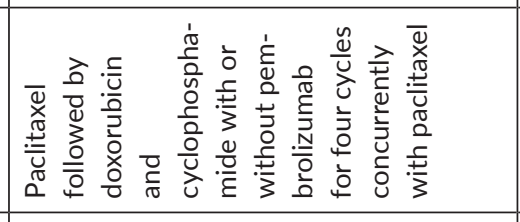 & 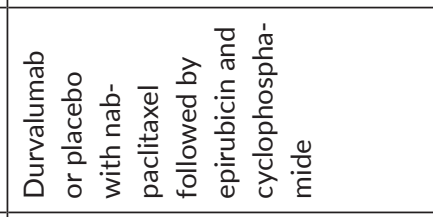 & 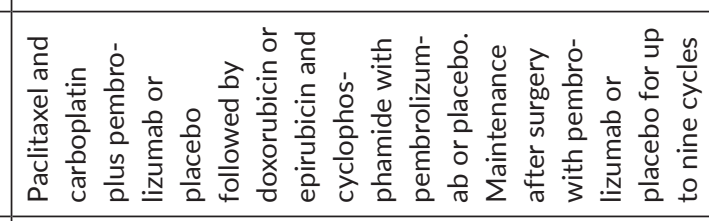 \\
\hline & 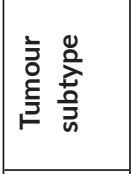 & 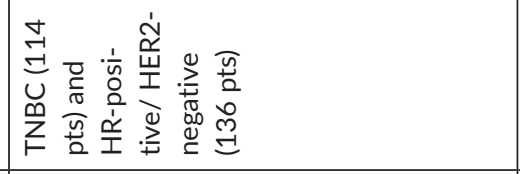 & 铝 & 售 \\
\hline & 带 奠 & 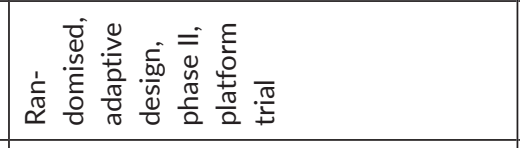 & 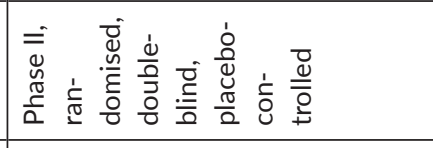 & 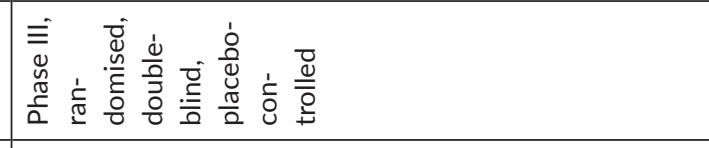 \\
\hline & 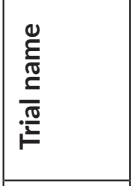 & 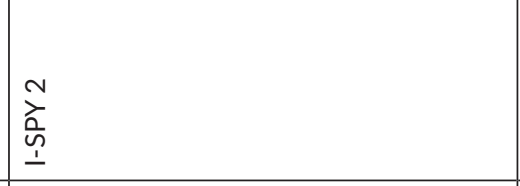 & 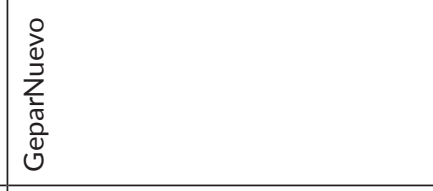 & 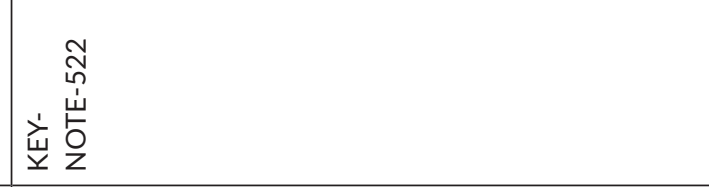 \\
\hline & 营 & 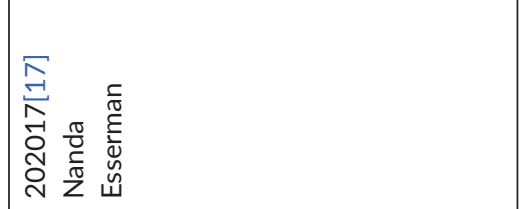 & 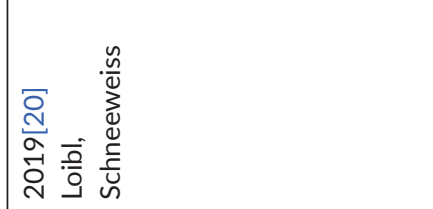 & 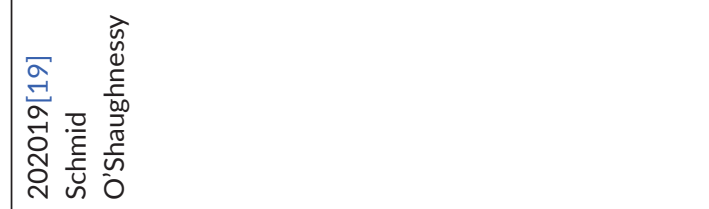 \\
\hline
\end{tabular}




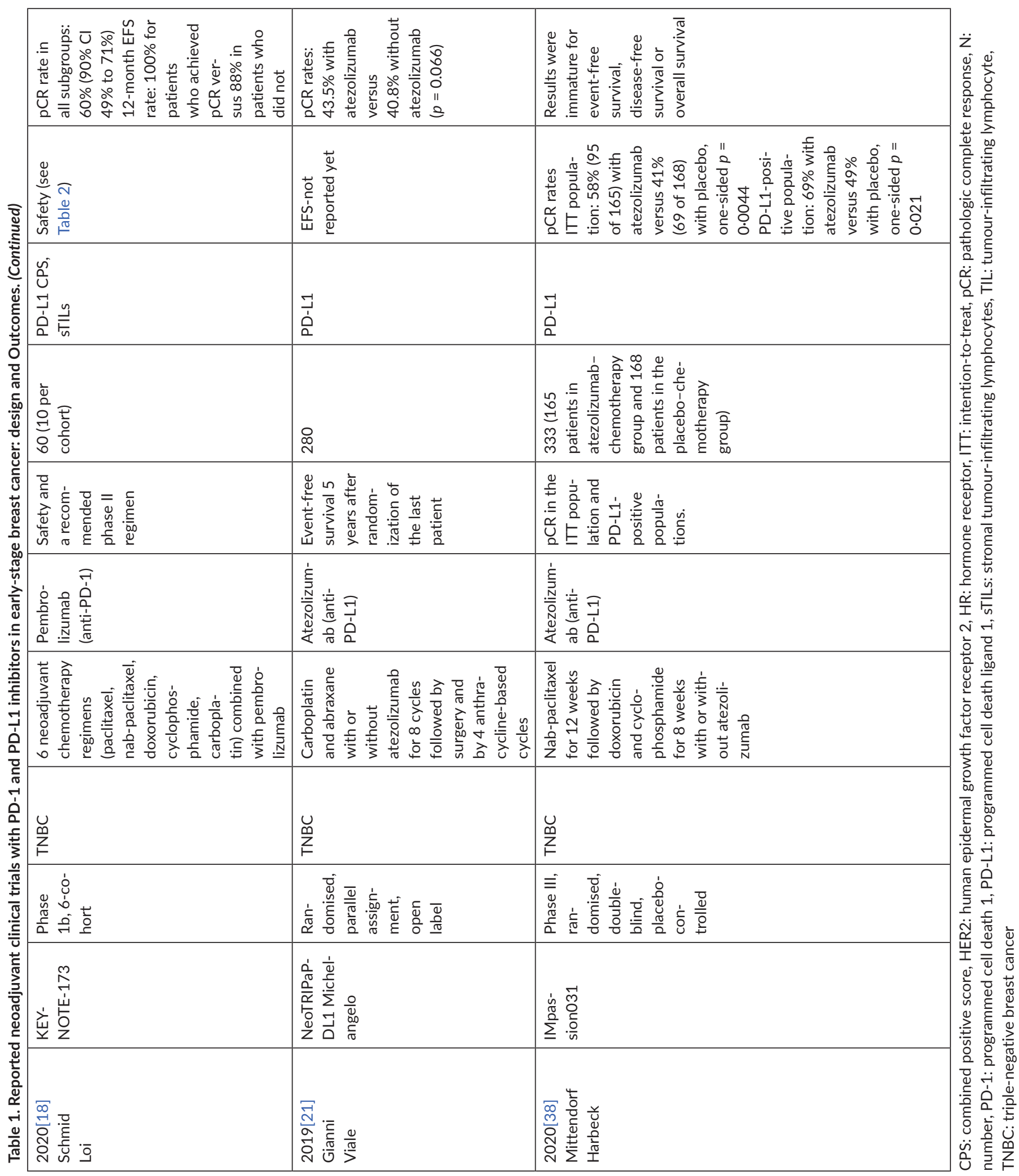


Table 2. Toxicity of neoadjuvant immunotherapy regimens in early-stage breast cancer trials.

\begin{tabular}{|c|c|c|c|c|}
\hline & $\mathrm{AE}$ & $\begin{array}{l}\text { Serious treatment- } \\
\text { related } A E\end{array}$ & Discontinuation rates due to $A E$ & Immune-related AE \\
\hline I-SPY 2 & $\begin{array}{l}\text { Common AE in pembroli- } \\
\text { zumab arm: } \\
\text { Fatigue: } 87 \% \\
\text { Nausea } 79.9 \% \\
\text { Diarrhoea: } 56.5 \% \\
\text { Sensory neuropathy: } 56.5 \%\end{array}$ & & & $\begin{array}{l}\text { The most common immune-related } \mathrm{AE} \\
\text { was } \\
\text { thyroid dysfunction } \\
\text { (hypothyroidism and hyperthyroidism) } \\
\text { in } 13 \% \text { ( } 9 \text { of } 69 \text { patients) who received } \\
\text { pembrolizumab }\end{array}$ \\
\hline GeparNuevo & $\begin{array}{l}\text { AEs were similar between } \\
\text { two groups (durvalumab } \\
\text { versus placebo), with the } \\
\text { exception of thyroid dys- } \\
\text { function (more frequent in } \\
\text { durvalumab-arm) }\end{array}$ & $\begin{array}{l}30(32.6 \%) \text { in the dur- } \\
\text { valumab and } 29(35.4) \\
\text { in the placebo arm }\end{array}$ & $\begin{array}{l}\text { Similar discontinuation rates } \\
\text { between patients who received } \\
\text { durvalumab versus placebo } \\
\text { Durvalumab } \\
\text { was discontinued in } 20 \text { (of 92) } \\
\text { patients in durvalumab arm com- } \\
\text { pared with } 17 \text { (of } 82 \text { ) } \\
\text { patients on placebo arm }\end{array}$ & $\begin{array}{l}\text { Thyroid dysfunction } \\
\text { Hyperthyroidism more common in } \\
\text { durvalumab-arm ( } 9.8 \text { versus } 1.2 \% \text { ) }\end{array}$ \\
\hline KEYNOTE-522 & $\begin{array}{l}99.0 \% \text { (of } 781 \text { patients) in } \\
\text { the pembrolizumab arm } \\
\text { and } 99.7 \% \text { (of 389) in the } \\
\text { placebo arm }\end{array}$ & $\begin{array}{l}32.5 \% \text { (pembrolizumab } \\
\text { arm) and } 19.5 \% \text { (pla- } \\
\text { cebo arm) }\end{array}$ & $\begin{array}{l}\text { 23.3\% (pembrolizumab arm) and } \\
12.3 \% \text { (placebo arm) }\end{array}$ & $\begin{array}{l}\text { Hypothyroidism } 13.7 \% \text { (pembrolizumab) } \\
\text { versus } 3.3 \% \text { (placebo) } \\
\text { Hyperthyroidism } 4.6 \% \text { (pembrolizumab) } \\
\text { versus } 1 \% \text { (placebo) } \\
\text { AE of interest, grade } \geq 3 \text {, in } \geq 10 \text { patients } \\
\text { was adrenal insufficiency (in } 1.3 \% \text { ) in the } \\
\text { pembrolizumab-group }\end{array}$ \\
\hline KEYNOTE-173 & $100 \%$ (60 patients) & $90 \%$ (54 of 60 patients) & $27 \%$ (16 of 60 patients) & $30 \%$ (18 of 60 patients) \\
\hline $\begin{array}{l}\text { NeoTRIPaPDL1 } \\
\text { Michelangelo }\end{array}$ & $\begin{array}{l}97.8 \% \text { (of } 138 \text { patients) } \\
\text { in the atezolizumab arm } \\
\text { and } 98.6 \% \text { (of 140) in the } \\
\text { chemotherapy arm }\end{array}$ & $\begin{array}{l}18.1 \% \text { (atezolizumab } \\
\text { arm) and } 5.7 \% \text { (chemo- } \\
\text { therapy arm) }\end{array}$ & $\begin{array}{l}\text { 25.4\% (atezolizumab arm) and } \\
25 \% \text { (chemotherapy arm) }\end{array}$ & $\begin{array}{l}\text { Atezolizumab arm: } \\
\text { Hypothyroidism: } 5.8 \% \text { Hyperthyroid- } \\
\text { ism:0.7\% } \\
\text { Colitis:1.5\% } \\
\text { Pacreatitis:1.5\% }\end{array}$ \\
\hline Impassion031 & $\begin{array}{l}\text { 99\% (atezolizumab arm) and } \\
\text { 99\% (chemotherapy arm) }\end{array}$ & $\begin{array}{l}23 \% \text { (atezolizumab arm) } \\
\text { and } 16 \% \text { (chemotherapy } \\
\text { arm) }\end{array}$ & $\begin{array}{l}\text { 23\% (atezolizumab arm) and 20\% } \\
\text { (chemotherapy arm) }\end{array}$ & $\begin{array}{l}\text { 18.1\% (atezolizumab arm) and 5.7\% } \\
\text { (chemotherapy arm) }\end{array}$ \\
\hline
\end{tabular}

AE: adverse events, EFS: event-free survival, HER2: human epidermal growth factor receptor 2, HR: hormone receptor, pCR: pathologic complete response,

TNBC: triple-negative breast cancer

More recently, the IMpassion031, a phase III, randomised, double-blind study, evaluating the use of immunotherapy in early-stage TNBC, met its primary endpoint [38]. Overall, 333 patients were randomised to receive neoadjuvant chemotherapy (nab-paclitaxel followed by doxorubicin and cyclophosphamide) combined with atezolizumab versus chemotherapy compared to placebo and chemotherapy, followed by maintenance therapy with atezolizumab. The primary endpoint was PCR in the intention-to-treat population and in the PD-L1-positive population. There was a significant increase in the $\mathrm{PCR}$ rate in patients who received atezolizumab compared to patients who received placebo, regardless of PD-L1 expression [38].

Except for I-SPY 2 trial that enrolled patients with high-proliferative, hormone-receptor-positive tumours in addition to TNBC, all the rest of the aforementioned trials focused on triple-negative disease. However, the intriguing findings of clinical benefit in high-proliferative hormone receptor-positive disease along with preliminary data of immunotherapeutic benefit in metastatic HER2-positive disease [39] highlight the interest to further evaluate the role of immunotherapy in other breast cancer subtypes. 


\section{Adverse events}

Studies on neoadjuvant immunotherapy combined with chemotherapy showed that these combinations are relatively well-tolerated and do not compromise the administration of treatment. Discontinuation rates were similar between patients who received immunotherapy versus placebo [19-21] (Table 2). Serious treatment-related adverse events were observed in $40 \%$ (24 of 60) of patients in KEYNOTE-173 [18] and 34\% (59 of 174) of patients in GeparNuevo (30 patients who received durvalumab and 29 who received placebo) [20]. Importantly, in KEYNOTE-522, a higher rate of serious adverse events was reported in $33 \%$ of patients who received pembrolizumab combined with chemotherapy compared to $20 \%$ of patients who received chemotherapy alone [19]. The majority of adverse events were attributed to chemotherapy. All grade immune-related toxicity was reported in $30 \%$ to $42 \%$ of patients [18, 19]. Most common immune-related adverse events were associated with thyroid dysfunction [17, 19,20]. Other common immune-related adverse events included colitis, pneumonitis, skin reactions and adrenal insufficiency. Grade 5 immune-related adverse events were not reported in most neoadjuvant trials [17, 18, 20]. However, there were three deaths in the pembrolizumab group, attributed to pneumonitis, pulmonary embolism and sepsis, reported in KEYNOTE-522 trial [19].

The safety profile reported in neoadjuvant studies with immunotherapy is in line with data from trials in the metastatic setting. Currently available data show that immunotherapy can be combined with chemotherapy in the neoadjuvant setting without compromising the administration of standard treatment and completion of surgery. However, these findings should be interpreted with caution. The administration of immunotherapeutic agents may be associated with irreversible toxicities, and therefore, longer follow-up data to establish the long-term safety of immunotherapy in the curative setting are warranted.

\section{Immunotherapy biomarkers}

Immunotherapy has changed the therapeutic landscape of cancer, providing improved clinical outcomes and long-term survival compared to chemotherapy agents in selected patients. However, not all patients benefit from this treatment, while a proportion of patients experiences serious adverse events. It is critical to identify predictive biomarkers of response, to accurately select patients who will benefit from immunotherapy and spare the rest from unnecessary toxicity and costs [40]. Various molecular alterations and immunological parameters have been suggested to predict benefit or resistance from immunotherapeutic agents in diverse tumour subtypes [41-45]. Neoadjuvant clinical trials provide an ideal setting for biomarker identification and validation. Thus, in patients with breast cancer receiving neoadjuvant immunotherapy, several biomarkers are being evaluated for their association with response to PD-1 or PD-L1 inhibitors, including PD-L1 expression and tumour-infiltrating lymphocytes (TILs) [20, 46].

Positive PD-L1 expression is currently used for selecting patients with metastatic TNBC for first-line treatment with atezolizumab and nab-paclitaxel [22]. Similarly, in the Keynote-355 study, the benefit of adding pembrolizumab was observed in PD-L1-positive patients only [47]. PD-L1 expression was assessed with different antibodies using different cut-offs. In IMpassion-130 trial, PD-L1 expression was assessed using the SP142 PD-L1 immunohistochemical assay (Ventana Medical Systems), while PD-L1 positivity was defined as the presence of stained tumour-infiltrating immune cells covering $\geq 1 \%$ of the tumour area [22]. On the contrary, PD-L1 protein expression in KEYNOTE-355 was determined using Combined Positive Score (CPS) (PD-L1 IHC 22C3 pharmDx, Agilent, Santa Clara, CA), defined as the number of PD-L1 staining cells (tumour cells, lymphocytes and macrophages) divided by the total number of viable tumour cells, multiplied by 100 [47]. Tumour was considered positive if CPS $\geq 1$. Despite the benefit seen in patients with PD-L1-positive advanced TNBC with the addition of immunotherapy to chemotherapy, there are no data that PD-L1 status can be used for selection of patients with early TNBC who will benefit from the addition of checkpoint inhibitors to neoadjuvant chemotherapy. In early-stage breast cancer trials evaluating the use of immunotherapy in the neoadjuvant setting, PD-L1 positivity was defined using different antibodies. In KEYNOTE-522 and KEYNOTE-173 trials, PD-L1 expression was assessed using the IHC 22C3 pharmDx assay CPS [18, 19]. Tumours with PD-L1 expression $\geq 1 \%$ were defined as positive. PCR rates were high with the addition of pembrolizumab, irrespectively of PD-L1 expression levels [19]. In KEYNOTE-522, patients with PD-L1-positive tumours, pCR rates were $68.9 \%$ for those in the pembrolizumab arm and $54.9 \%$ for those in the placebo arm. In patients with PD-L1-negative tumours, pCR rates were $45.3 \%$ for those who received pembrolizumab and chemotherapy and $30.3 \%$ for those who received placebo and chemotherapy. Among the 60 patients enrolled in KEYNOTE-173, pre-treatment PD-L1 CPS was assessed 
for 52 (87\%) [18]. PD-L1 CPS was associated with higher pCR rates (area under the receiver operating characteristic curve (AUROC) $=0.658$ ). Specifically, pCR rates were $60 \%$ versus $40 \%$ in patients with PD-L1 CPS $\geq 1$ and $<1$, respectively. In the GeparNuevo trial, PD-L1 expression was evaluated using the Ventana SP263 antibody (Ventana Medical Systems Inc., Tucson, AZ) and was defined as the proportion of tumour cells with membranous staining (PD-L1-TC) and proportion of TILs with membranous or cytoplasmic staining (PD-L1-IC) [20]. If any of these proportions were $\geq 1 \%$, tumours were considered PD-L1 positive. Details on the assays used for PD-L1 expression is shown in Table 3 . Even though $p C R$ rates were higher in patients with PD-L1 positive compared to PD-L1-negative tumours $(54.3 \%$ versus $30.0 \%$, respectively, $p=$ 0.048), PD-L1 expression did not predict for response to durvalumab [20]. Patients who received durvalumab had numerically higher pCR rates when tumours were PD-L1-positive compared to PD-L1-negative ( $58.0 \%$ versus $44.4 \%$, respectively, $p=0.445$ ); however, this difference was not statistically significant. Despite differences in the assessment of PD-L1 expression regarding the use of diverse antibodies and scoring systems, this biomarker does not seem to be predictive for response to immunotherapy in the neoadjuvant setting.

Increased TIL concentration has been identified as a predictor of response to neoadjuvant chemotherapy in all molecular subtypes of breast cancer $[48,49]$. In addition, there are data suggesting a prognostic effect for TIL levels varying according to the tumour subtype [48, 50-53]. A pooled analysis of six randomised trials including 3771 patients with breast cancer who received neoadjuvant combination chemotherapy demonstrated that patients with high TILs had higher rates of pCR, irrespective of the tumour subtype [48]. Importantly, the increase in TILs was associated with longer overall survival in patients with TNBC, but not in patients with HER2-positive (no difference) or hormone receptor-positive/HER2-negative tumours (shorter overall survival). Whether this immunologic parameter can be used as a biomarker predicting response to immunotherapy is under investigation [19]. Preliminary data from GeparNuevo trial showed that stromal TILs were not predictive for durvalumab response [20]. In fact, baseline stromal TILs (sTILs) predicted higher pCR rates not only in patients who received durvalumab but also in patients who received placebo. Interestingly, during the window-phase of the trial, the increase of intratumoural TILs, from baseline to post-window samples, was independently associated with high $\mathrm{pCR}$ rates in the durvalumab group $(\mathrm{OR} 9.36,95 \% \mathrm{Cl} 1.26-69.65, p$ $=0.029$ ), but not in patients who received placebo (OR 1.22, 95\% Cl 0.65-2.27, $p=0.540$ ). In KEYNOTE-173, of 60 patients who enrolled in the trial, sTILs were assessed for 53 (88\%) patients before treatment and for 49 patients (82\%) after one dose of pembrolizumab [18]. Median pre-treatment and on-treatment sTIL levels were higher for patients with $\mathrm{pCR}$. In addition, higher pre-treatment and on-treatment sTILs were associated with higher pCR rates (AUROC 0.653 and 0.690 , respectively). The correlation between PD-L1 CPS and sTILs (pre- and on-treatment) was moderate to strong. These preliminary data suggest that, while there seems to be an association of high levels of TILs with high pCR rates, TILs cannot be used alone as a biomarker predicting response to immunotherapy. Further research is warranted to determine the optimal cut-offs or the use of TIL expression as a continuous variable to form a standardised methodology for evaluating TILs.

Moreover, high expression of immune-related gene signatures has been associated with higher pCR rates to neoadjuvant anthracycline-/ taxane-based chemotherapy [54]. High levels of immune-related gene signatures have been associated with high levels of TILs [55]; however, the role of immune-related gene signatures to predict benefit from immunotherapy is unclear.

Table 3. Comparison of PD-L1 used in early-stage breast cancer.

\begin{tabular}{|l|l|l|l|l|}
\hline Antibody & Developer & Cut-off & Drug & Clinical trial \\
\hline $\begin{array}{l}\text { IHC 22C3 pharmDx } \\
\text { assay }\end{array}$ & Agilent, Santa Clara, California & CPS $\geq 1 \%$ & Pembrolizumab & $\begin{array}{l}\text { KEYNOTE-522 KEY- } \\
\text { NOTE-173 }\end{array}$ \\
\hline IHC SP263 assay & $\begin{array}{l}\text { Ventana Medical Systems Inc., } \\
\text { Tucson, Arizona }\end{array}$ & $\begin{array}{l}\text { Proportion of tumour cells with mem- } \\
\text { branous staining and/or proportion of } \\
\text { TILs with membranous or cytoplasmic } \\
\text { staining } \geq 1 \%,\end{array}$ & Durvalumab & GeparNuevo \\
\hline IHC SP142 assay & $\begin{array}{l}\text { Ventana Medical Systems Inc., } \\
\text { Tucson, Arizona }\end{array}$ & Immune cells $\geq 1 \%$ & Atezolizumab & Impassion031 \\
\hline
\end{tabular}

CPS: combined positive score, IHC: immunohistochemistry, TILs: tumour-infiltrating lymphocytes 


\section{New strategies for immunotherapy trials in early-stage breast cancer}

There is a significant number of clinical trials evaluating the clinical benefit from immunotherapeutic agents administered as neoadjuvant treatment of patients with breast cancer (Table 4). In these trials, various immunotherapeutic agents are administered often in combination with chemotherapy.

Other clinical trials evaluate combinations of immunotherapy with targeted agents (i.e., CDK4/6 inhibitors, anti-HER2 agents). For instance, CDK4/6 inhibitors have been shown to enhance anti-tumour immune response, thus acting synergistically with immunotherapeutic agents [56-58]. In addition, several trials are evaluating the benefit and safety of vaccines, either against personalised cancer cell epitopes or commonly overexpressed proteins, such as HER2. Other trials are assessing PD-1/PD-L1 inhibitors in combination with other immunotherapy agents, intratumoural injections of immunotherapeutic agents (oncolytic viruses) or ex vivo expanded activated T cells. Other interesting approaches are the use of cryoablation [59] or stereotactic radiotherapy [60] to render a tumour immunogenic, as well as an in situ tumour vaccine or the use of anti-CD73 antibodies to block the adenosine pathway.

A significant proportion of immunotherapy trials has initially focused on TNBC, possibly due to high PD-L1 expression and TIL levels in those tumours compared to other subtypes. Nevertheless, a number of immunotherapy trials have been initiated in high-proliferative hormone receptor-positive/HER2-negative and HER2-positive tumours (Table 4).

Table 4. Ongoing neoadjuvant trials with immunotherapeutic agents.

\begin{tabular}{|c|c|c|c|c|}
\hline Trial name & Immunotherapeutic agent & Tumour subtype & Trial type & Identifier \\
\hline \multicolumn{5}{|l|}{ Trials with PD-1/PD-L1 inhibitors and chemotherapy } \\
\hline PHOENIX DDR/Anti-PD-L1 Trial & Durvalumab & TNBC & Window of opportunity & NCT03740893 \\
\hline $\begin{array}{l}\text { Safety and Efficacy of Durvalumab Combined to } \\
\text { Neoadjuvant Chemotherapy in Localised Luminal } \\
\text { B HER2(-) and Triple-Negative Breast Cancer (B- } \\
\text { IMMUNE) }\end{array}$ & Durvalumab & $\begin{array}{l}\text { HR-positive, } \\
\text { HER2-negative }\end{array}$ & Phase lb/II, open label & NCT03356860 \\
\hline $\begin{array}{l}\text { Neoadjuvant MEDI } 4736 \text { Concomitant With } \\
\text { Weekly Nab-paclitaxel and Dose-dense AC for } \\
\text { Stage I-III Triple-Negative Breast Cancer }\end{array}$ & Durvalumab & TNBC & Phase I/II, single arm & NCT02489448 \\
\hline $\begin{array}{l}\text { Study of Immunotherapy in Combination With } \\
\text { Chemotherapy in HER2-negative Inflammatory } \\
\text { Breast Cancer (PELICAN) }\end{array}$ & Pembrolizumab & HER2-negative & $\begin{array}{l}\text { Phase II randomised open- } \\
\text { label }\end{array}$ & NCT03515798 \\
\hline $\begin{array}{l}\text { Neoadjuvant Pembrolizumab + Decitabine Fol- } \\
\text { lowed by Std Neoadj Chemo for Locally Advanced } \\
\text { HER2- Breast Ca }\end{array}$ & Pembrolizumab & HER2-negative & $\begin{array}{l}\text { Phase II, 2-cohort, open- } \\
\text { label }\end{array}$ & NCT02957968 \\
\hline $\begin{array}{l}\text { Neoadjuvant Phase II Study of Pembrolizumab } \\
\text { And Carboplatin Plus Docetaxel in Triple-Negative } \\
\text { Breast Cancer (NeoPACT) }\end{array}$ & Pembrolizumab & TNBC & Phase II, open label & NCT03639948 \\
\hline $\begin{array}{l}\text { Carboplatin and Paclitaxel With or Without } \\
\text { Atezolizumab Before Surgery in Treating Patients } \\
\text { With Newly Diagnosed, Stage II-III Triple-Negative } \\
\text { Breast Cancer }\end{array}$ & Atezolizumab & TNBC & $\begin{array}{l}\text { Phase II, randomised, open } \\
\text { label }\end{array}$ & NCT02883062 \\
\hline $\begin{array}{l}\text { Nab-Paclitaxel and Atezolizumab Before Surgery } \\
\text { in Treating Patients With Triple-Negative Breast } \\
\text { Cancer }\end{array}$ & Atezolizumab & TNBC & Phase II, open label & NCT02530489 \\
\hline
\end{tabular}


Table 4. Ongoing neoadjuvant trials with immunotherapeutic agents. (Continued)

\begin{tabular}{|c|c|c|c|c|}
\hline $\begin{array}{l}\text { Pembrolizumab in Treating Patients With Hor- } \\
\text { mone Receptor-Positive, Localised Inflammatory } \\
\text { Breast Cancer Who Are Receiving Hormone } \\
\text { Therapy and Did Not Achieve a Pathological Com- } \\
\text { plete Response to Chemotherapy }\end{array}$ & Pembrolizumab & $\begin{array}{l}\text { HR-positive, } \\
\text { HER2-negative }\end{array}$ & Phase II, open label & NCT02971748 \\
\hline $\begin{array}{l}\text { Pembrolizumab in Treating Patients With Triple- } \\
\text { Negative Breast Cancer }\end{array}$ & Pembrolizumab & TNBC & $\begin{array}{l}\text { Phase III, randomised, } \\
\text { open label }\end{array}$ & NCT02954874 \\
\hline $\begin{array}{l}\text { Neoadjuvant Pembrolizumab(Pbr)/Nab-Paclitaxel } \\
\text { Followed by Pbr/Epirubicin/Cyclophosphamide in } \\
\text { TNBC (NIB) }\end{array}$ & Pembrolizumab & TNBC & $\begin{array}{l}\text { Phase II, one-arm, open- } \\
\text { label }\end{array}$ & NCT03289819 \\
\hline $\begin{array}{l}\text { Study of Pembrolizumab (MK-3475) Versus } \\
\text { Placebo in Combination With Neoadjuvant } \\
\text { Chemotherapy \& Adjuvant Endocrine Therapy in } \\
\text { the Treatment of Early-Stage Oestrogen Recep- } \\
\text { tor-Positive, Human Epidermal Growth Factor } \\
\text { Receptor 2-Negative (ER+/HER2-) Breast Cancer } \\
\text { (MK-3475-756/KEYNOTE-756) }\end{array}$ & Pembrolizumab & $\begin{array}{l}\text { HR-positive, } \\
\text { HER2-negative }\end{array}$ & $\begin{array}{l}\text { Phase III, randomised, } \\
\text { double-blind }\end{array}$ & NCT03725059 \\
\hline $\begin{array}{l}\text { Trial of Nivolumab With Chemotherapy as Neoad- } \\
\text { juvant Treatment in Inflammatory Breast Cancer }\end{array}$ & Nivolumab & $\begin{array}{l}\text { TNBC or HR- } \\
\text { positive, HER2- } \\
\text { negative }\end{array}$ & Phase II, open label & NCT03742986 \\
\hline $\begin{array}{l}\text { Study of Nivolumab Versus Placebo in Participants } \\
\text { With High-Risk Breast Cancer (CheckMate 7FL) }\end{array}$ & Nivolumab & $\begin{array}{l}\text { HR-positive, } \\
\text { HER2-negative }\end{array}$ & $\begin{array}{l}\text { Phase III, randomised, } \\
\text { double-blind, placebo- } \\
\text { controlled }\end{array}$ & NCT04109066 \\
\hline $\begin{array}{l}\text { Clinical Trial of Neoadjuvant Chemotherapy With } \\
\text { Atezolizumab or Placebo in Patients With Triple- } \\
\text { Negative Breast Cancer Followed After Surgery by } \\
\text { Atezolizumab or Placebo }\end{array}$ & Atezolizumab & TNBC & $\begin{array}{l}\text { Phase III, randomised, } \\
\text { double-blind, }\end{array}$ & NCT03281954 \\
\hline $\begin{array}{l}\text { Neoadjuvant Treatment of HER2-Positive Early } \\
\text { High-Risk and Locally Advanced Breast Cancer } \\
\text { (APTneo) }\end{array}$ & Atezolizumab & HER2-positive & $\begin{array}{l}\text { Phase III, randomised, } \\
\text { open label }\end{array}$ & NCT03595592 \\
\hline $\begin{array}{l}\text { A Study to Investigate Atezolizumab and Chemo- } \\
\text { therapy Compared With Placebo and Chemo- } \\
\text { therapy in the Neoadjuvant Setting in Participants } \\
\text { With Early-Stage Triple-Negative Breast Cancer } \\
\text { (IMpassion031) }\end{array}$ & Atezolizumab & TNBC & $\begin{array}{l}\text { Phase III, double-blind, } \\
\text { randomised, placebo- } \\
\text { controlled }\end{array}$ & NCT03197935 \\
\hline \multicolumn{5}{|c|}{ Trials with PD-1/PD-L1 inhibitors and CDK4/6 inhibitors } \\
\hline $\begin{array}{l}\text { Neoadjuvant Study of Abemaciclib, Durvalumab } \\
\text { and an Aromatase Inhibitor Early-Stage Breast } \\
\text { Cancer }\end{array}$ & Durvalumab & $\begin{array}{l}\text { HR-positive, } \\
\text { HER2-negative }\end{array}$ & Early Phase I & NCT04088032 \\
\hline $\begin{array}{l}\text { A Study of Neoadjuvant Nivolumab + Abemaciclib } \\
\text { or Palbociclib + Anastrozole in Post-Menopausal } \\
\text { Women and Men With Primary Breast Cancer } \\
\text { (CheckMate 7A8) }\end{array}$ & Nivolumab & $\begin{array}{l}\text { HR-positive, } \\
\text { HER2-negative }\end{array}$ & $\begin{array}{l}\text { Phase II, randomised, non- } \\
\text { comparative, multi-arm, }\end{array}$ & NCT04075604 \\
\hline $\begin{array}{l}\text { Neoadjuvant Tamoxifen, Palbociclib, Avelumab in } \\
\text { Oestrogen Receptor-Positive Breast Cancer } \\
\text { (ImmunoADAPT) }\end{array}$ & Avelumab & HER2-positive & Phase II, open label & NCT03573648 \\
\hline
\end{tabular}


Table 4. Ongoing neoadjuvant trials with immunotherapeutic agents. (Continued)

\begin{tabular}{|c|c|c|c|c|}
\hline \multicolumn{5}{|c|}{ Trials with PD-1/PD-L1 inhibitors and anti-HER2 treatment } \\
\hline $\begin{array}{l}\text { TAHP for Patients With HER2-positive Early } \\
\text { Breast Cancer and Subsequent AHP Adjuvant } \\
\text { Therapy After Surgery }\end{array}$ & Atezolizumab & HER2-positive & Phase IB-II & NCT03881878 \\
\hline $\begin{array}{l}\text { Atezolizumab in combination with trastuzumab } \\
\text { emtansine or with trastuzumab and pertuzumab } \\
\text { in patients with HER2-positive breast cancer and } \\
\text { atezolizumab with doxorubicin and cyclophospha- } \\
\text { mide in HER2-negative breast cancer }\end{array}$ & Atezolizumab & HER2-positive & Phase lb, multi-cohort & NCT02605915 \\
\hline $\begin{array}{l}\text { Neoadjuvant Her2-targeted Therapy and Immuno- } \\
\text { therapy With Pembrolizumab }\end{array}$ & Pembrolizumab & HER2-positive & $\begin{array}{l}\text { Phase II open-label, ran- } \\
\text { domised }\end{array}$ & NCT03747120 \\
\hline $\begin{array}{l}\text { A Study With Pembrolizumab in Combination } \\
\text { With Dual Anti-HER2 Blockade With Trastuzumab } \\
\text { and Pertuzumab in Early Breast Cancer Patients } \\
\text { With Molecular HER2-enriched Intrinsic Subtype } \\
\text { (Keyriched-1) }\end{array}$ & Pembrolizumab & HER2-positive & $\begin{array}{l}\text { Phase II, prospective, } \\
\text { single arm, open label }\end{array}$ & NCT03988036 \\
\hline $\begin{array}{l}\text { A Study To Evaluate the Efficacy and Safety Of } \\
\text { Atezolizumab or Placebo in Combination With } \\
\text { Neoadjuvant Doxorubicin + Cyclophosphamide } \\
\text { Followed By Paclitaxel + Trastuzumab + Per- } \\
\text { tuzumab In Early Her2-Positive Breast Cancer } \\
\text { (IMpassion050) }\end{array}$ & Atezolizumab & HER2-positive & $\begin{array}{l}\text { Phase III, randomised, } \\
\text { double-Blind, placebo- } \\
\text { controlled }\end{array}$ & NCT03726879 \\
\hline $\begin{array}{l}\text { Improving Pre-operative Systemic Therapy for Hu- } \\
\text { man Epidermal Growth Factor Receptor } 2 \text { (HER2) } \\
\text { Amplified Breast Cancer (PREDIX II HER2) }\end{array}$ & Atezolizumab & HER2-positive & $\begin{array}{l}\text { Phase II, randomised, open } \\
\text { label }\end{array}$ & NCT03894007 \\
\hline \multicolumn{5}{|c|}{ Trials with PD-1/PD-L1 inhibitors and Radiation treatment } \\
\hline $\begin{array}{l}\text { Neo-adjuvant Chemotherapy Combined With } \\
\text { Stereotactic Body Radiotherapy to the Primary } \\
\text { Tumour +/- Durvalumab +/- Oleclumab in Luminal } \\
\text { B Breast Cancer: (Neo-CheckRay) }\end{array}$ & Durvalumab, Oleclumab & Luminal B & $\begin{array}{l}\text { Phase II, randomised, } \\
\text { open-label }\end{array}$ & NCT03875573 \\
\hline $\begin{array}{l}\text { Breast Cancer Study of Pre-Operative Pembroli- } \\
\text { zumab + Radiation }\end{array}$ & Pembrolizumab & $\begin{array}{l}\text { TNBC or HR- } \\
\text { positive, HER2- } \\
\text { negative }\end{array}$ & $\begin{array}{l}\text { Phase I/II, single arm with } \\
\text { two cohorts }\end{array}$ & NCT03366844 \\
\hline \multicolumn{5}{|l|}{ Trials with vaccines } \\
\hline $\begin{array}{l}\text { HER2 Directed Dendritic Cell Vaccine During } \\
\text { Neoadjuvant Therapy of HER2+Breast Cancer }\end{array}$ & $\begin{array}{l}\text { Dendritic Cell Vaccine } \\
\text { (DC1) }\end{array}$ & HER2-positive & Early Phase I & NCT03387553 \\
\hline $\begin{array}{l}\text { HER-2 Pulsed DC Vaccine to Prevent Recurrence } \\
\text { of Invasive Breast Cancer Post Neoadjuvant } \\
\text { Chemotherapy }\end{array}$ & $\begin{array}{l}\text { HER-2 pulsed Dendritic } \\
\text { Cell Vaccine }\end{array}$ & HER2-positive & Phase I & NCT02061423 \\
\hline $\begin{array}{l}\text { Safety and Immunogenicity of a Personalised } \\
\text { Synthetic Long Peptide Breast Cancer Vaccine } \\
\text { Strategy in Patients With Persistent Triple- } \\
\text { Negative Breast Cancer Following Neoadjuvant } \\
\text { Chemotherapy }\end{array}$ & $\begin{array}{l}\text { Personalised synthetic } \\
\text { long peptide vaccine }\end{array}$ & TNBC & Phase I, single-arm & NCT02427581 \\
\hline $\begin{array}{l}\text { Safety and Immunogenicity of a Personalised Poly- } \\
\text { epitope DNA Vaccine Strategy in Breast Cancer } \\
\text { Patients With Persistent Triple-Negative Disease } \\
\text { Following Neoadjuvant Chemotherapy }\end{array}$ & $\begin{array}{l}\text { Personalised polyepitope } \\
\text { DNA vaccine }\end{array}$ & TNBC & Phase I open-label & NCT02348320 \\
\hline
\end{tabular}


Table 4. Ongoing neoadjuvant trials with immunotherapeutic agents. (Continued)

\begin{tabular}{|c|c|c|c|c|}
\hline $\begin{array}{l}\text { Safety and Immune Response to a Mammaglobin- } \\
\text { A DNA Vaccine In Breast Cancer Patients Under- } \\
\text { going Neoadjuvant Endocrine Therapy }\end{array}$ & $\begin{array}{l}\text { Mammaglobin-A DNA } \\
\text { Vaccine }\end{array}$ & $\begin{array}{l}\text { HR-positive, } \\
\text { HER2-negative }\end{array}$ & Phase IB & NCT02204098 \\
\hline Vaccination of High-Risk Breast Cancer Patients & Chemovax & HR-positive & Phase I/II study, single-arm & NCT02229084 \\
\hline $\begin{array}{l}\text { Phase II Trial of Combination Immunotherapy } \\
\text { With NeuVax and Trastuzumab in High-risk } \\
\text { HER2+ Breast Cancer Patients }\end{array}$ & NeuVax vaccine & HER2-positive & $\begin{array}{l}\text { Phase II, prospective, } \\
\text { randomised, single-blinded, } \\
\text { placebo-controlled }\end{array}$ & NCT02297698 \\
\hline $\begin{array}{l}\text { Vaccination of Triple-Negative Breast Cancer } \\
\text { Patients }\end{array}$ & $\begin{array}{l}\text { P10s-PADRE with MON- } \\
\text { TANIDE }{ }^{\mathrm{M}} \text { ISA } 51 \text { VG }\end{array}$ & TNBC & $\begin{array}{l}\text { Phase II, randomised two- } \\
\text { arm, open-label }\end{array}$ & NCT02938442 \\
\hline $\begin{array}{l}\text { Folate Receptor Alpha Peptide Vaccine With } \\
\text { GM-CSF in Patients With Triple-Negative Breast } \\
\text { Cancer }\end{array}$ & Low dose FRa vaccine & TNBC & Phase II , randomised & NCT02593227 \\
\hline $\begin{array}{l}\text { TPIV100 and Sargramostim for the Treatment of } \\
\text { HER2-Positive, Stage II-III Breast Cancer in Pa- } \\
\text { tients With Residual Disease After Chemotherapy } \\
\text { and Surgery }\end{array}$ & Vaccine Therapy & HER2-positive & Phase II, randomised & NCT04197687 \\
\hline \multicolumn{5}{|c|}{ Trials with PD-1/PD-L1 inhibitors in combination with other immunotherapy drugs } \\
\hline $\begin{array}{l}\text { Combination of Talimogene Laherparepvec With } \\
\text { Atezolizumab in Early Breast Cancer (PROMETEO) }\end{array}$ & Atezolizumab, T-VEC & $\begin{array}{l}\text { TNBC or HR- } \\
\text { positive, HER2- } \\
\text { negative }\end{array}$ & $\begin{array}{l}\text { Window opportunity, } \\
\text { single arm, exploratory }\end{array}$ & NCT03802604 \\
\hline $\begin{array}{l}\text { M7824 in Treating Patients With Stage II-III } \\
\text { HER2-Positive Breast Cancer }\end{array}$ & $\begin{array}{l}\text { anti-PD-L1/TGFbetaRII } \\
\text { fusion protein M7824 }\end{array}$ & HER2-positive & Phase I & NCT03620201 \\
\hline $\begin{array}{l}\text { Converting HR+ Breast Cancer Into an Individual- } \\
\text { ised Vaccine (CBCV) }\end{array}$ & Pembrolizumab, CDX-301 & $\begin{array}{l}\text { HR-positive, } \\
\text { HER2-negative }\end{array}$ & $\begin{array}{l}\text { phase II, randomised open- } \\
\text { label }\end{array}$ & NCT03804944 \\
\hline $\begin{array}{l}\text { Peri-Operative Ipilimumab+Nivolumab and Cryo- } \\
\text { ablation Versus Standard Care in Women With } \\
\text { Triple-Negative Breast Cancer }\end{array}$ & Ipilimumab, nivolumab & TNBC & $\begin{array}{l}\text { Phase II, randomised, open } \\
\text { label }\end{array}$ & NCT03546686 \\
\hline $\begin{array}{l}\text { TAC Chemotherapy and Pembrolizumab Plus } \\
\text { Interleukin-12 Gene Therapy and L-NMMA in } \\
\text { Triple-Negative Breast Cancer }\end{array}$ & Pembrolizumab & TNBC & $\begin{array}{l}\text { Phase II, prospective, } \\
\text { single arm, open label }\end{array}$ & NCT04095689 \\
\hline $\begin{array}{l}\text { Durvalumab and Endocrine Therapy in ER+/Her2- } \\
\text { Breast Cancer After CD8+ Infiltration Effective } \\
\text { Immune-Attractant Exposure (ULTIMATE) }\end{array}$ & $\begin{array}{l}\text { Durvalumab, Immune- } \\
\text { attractant }\end{array}$ & $\begin{array}{l}\text { HR-positive, } \\
\text { HER2-negative }\end{array}$ & $\begin{array}{l}\text { Phase II, open-label, single } \\
\text { group assignment }\end{array}$ & NCT02997995 \\
\hline $\begin{array}{l}\text { Durvalumab and Tremelimumab Before Surgery in } \\
\text { Treating Patients With Hormone Receptor-Posi- } \\
\text { tive, HER2-Negative Stage II-III Breast Cancer }\end{array}$ & $\begin{array}{l}\text { Durvalumab and Tremeli- } \\
\text { mumab }\end{array}$ & $\begin{array}{l}\text { HR-positive, } \\
\text { HER2-negative }\end{array}$ & Early phase I & NCT03132467 \\
\hline $\begin{array}{l}\text { Pre-operative Immunotherapy Combination Strat- } \\
\text { egies in Breast Cancer (ECLIPSE) }\end{array}$ & Atezolizumab & $\begin{array}{l}\text { HR-positive, } \\
\text { HER2-negative }\end{array}$ & $\begin{array}{l}\text { Phase II, open label, win- } \\
\text { dow of opportunity }\end{array}$ & NCT03395899 \\
\hline \multicolumn{5}{|l|}{ Other immunotherapeutic approaches } \\
\hline $\begin{array}{l}\text { Immunogenicity and Safety of DCs in Breast } \\
\text { Cancer (TEBICA) }\end{array}$ & Dendritic cells & All & Phase I/II, randomised & NCT03450044 \\
\hline $\begin{array}{l}\text { Targeted T Cells After Neoadjuvant Chemotherapy } \\
\text { in Treating Women With Stage II or III Breast } \\
\text { Cancer Undergoing Surgery }\end{array}$ & $\begin{array}{l}\text { HER2Bi-armed activated } \\
\text { T cells }\end{array}$ & TNBC & Phase II, open label & NCT01147016 \\
\hline $\begin{array}{l}\text { Intratumoural TriMix Injections in Early Breast } \\
\text { Cancer Patients (TMBA) }\end{array}$ & Trimix & All & Phase I & NCT03788083 \\
\hline
\end{tabular}




\section{Perspectives and conclusions}

Neoadjuvant trials represent valuable platforms to test the efficacy of innovative drugs and/or a combination of treatments and evaluate the predictive value of new biomarkers. The PD-1 inhibitor pembrolizumab combined with neoadjuvant chemotherapy significantly increased the pCR rates in patients with TNBC. Long-term outcome data from this trial are eagerly awaited. Ongoing trials are testing other PD-1/PD-L1 inhibitors in combination with neoadjuvant chemotherapy in TNBC. Preliminary data show that the addition of immunotherapy to neoadjuvant chemotherapy might also be active in other tumour subtypes beyond TNBC. However, not all clinical trials demonstrated significant differences in clinical outcomes with the addition of immunotherapy to neoadjuvant chemotherapy. These differences might be related to patient selection, trials' sample size, use of different immunotherapy drugs (PD-L1 versus PD-1 inhibitors), different chemotherapy backbone regimens and/or continuation of immunotherapy after curative surgery.

In addition to chemotherapy, which has been shown to increase tumour immunogenicity, other targeted agents such as anti-HER2 agents or the CDK46 inhibitors or other immunotherapeutic agents are being tested in combination with PD-1/PD-L1 inhibitors. Other agents, including bevacizumab, have been shown to increase the pCR rates without any difference in long-term outcomes. Therefore, we still need to determine whether $\mathrm{pCR}$ after neoadjuvant immunotherapy combined with chemotherapy is associated with improved long-term outcomes. Existing biomarkers, including PD-L1, seem to be ineffective in the neoadjuvant setting for the accurate selection of patients who will benefit from checkpoint blockade. Immunotherapy is associated with potentially irreversible toxicities and prohibitive costs. Therefore, it is critical to identify patients, where the escalation of treatment is required to improve outcomes, along with robust predictive biomarkers of efficacy and toxicity, to select patients who will benefit from the addition of neoadjuvant immunotherapy, thus sparing the rest from an ineffective treatment with unnecessary toxicity and treatment costs. Ultimately, patients with early-stage breast cancer will receive individualised management based on their tumour clinicopathological, molecular and immune-related characteristics.

\section{Conflicts of interest}

E.F.: Stock ownership: GENPREX INC, ARIAD, Deciphera Pharmaceuticals, Inc. Travel grant: Merck, Pfizer and K.A.M Oncology/Hematology. Advisory: LEO Pharma. Speaker fees: Roche, Pfizer

M.I.: Consultant or advisory role: Celgene, Novartis, Pfizer, Seattle Genetics, Tesaro; Speaker Honoraria: Novartis; travel grants: Pfizer, Amgen; research grants to my Institute: Roche, Menarini Silicon Biosystems, Janssen Diagnostics, Pfizer.

\section{Financial conflicts of interest in relation to this manuscript}

The authors have no financial conflicts of interest.

\section{Funding statement}

The authors did not receive any funding for the preparation of this review article.

\section{References}

1. Wang S-L, Li Y-X, and Song Y-W, et al (2011) Triple-negative or HER2-positive status predicts higher rates of locoregional recurrence in node-positive breast cancer patients after mastectomy Int J Radiat Oncol Biol Phys 80(4) 1095-1101 https://doi.org/10.1016/j. ijrobp.2010.03.038

2. Arvold ND, Taghian AG, and Niemierko A, et al (2011) Age, breast cancer subtype approximation, and local recurrence after breastconserving therapy J Clin Oncol 29(29) 3885-3891 https://doi.org/10.1200/JCO.2011.36.1105 PMID: 21900114 PMCID: 3189090 
3. Chia S, Swain SM, and Byrd DR, et al (2008) Locally advanced and inflammatory breast cancer J Clin Oncol 26(5) 786-790 https://doi. org/10.1200/JCO.2008.15.0243 PMID: 18258987

4. Arlow RL, Paddock LE, and Niu X, et al (2018) Breast-conservation therapy after neoadjuvant chemotherapy does not compromise 10-year breast cancer-specific mortalit Am J Clin Oncol 41(12) 1246-1251 https://doi.org/10.1097/COC.0000000000000456 PMID: 29782362

5. Spring L, Greenup R, and Niemierko A, et al (2017) Pathologic complete response after neoadjuvant chemotherapy and long-term outcomes among young women with breast cancer J Natl Compr Canc Netw 15(10) 1216-1223 https://doi.org/10.6004/jnccn.2017.0158 PMID: 28982747

6. Broglio KR, Quintana M, and Foster M, et al (2016) Association of pathologic complete response to neoadjuvant therapy in her2-positive breast cancer with long-term outcomes: a meta-analysis JAMA Oncol 2(6) 751-760 https://doi.org/10.1001/jamaoncol.2015.6113 PMID: 26914222

7. Hahnen E, Lederer B, and Hauke J, et al (2017) Germline mutation status, pathological complete response, and disease-free survival in triple-negative breast cancer: secondary analysis of the GeparSixto randomized clinical trial. JAMA Oncol 3(10) 1378-1385 https://doi. org/10.1001/jamaoncol.2017.1007 PMID: 28715532 PMCID: 5710508

8. Fayanju OM, Ren Y, and Thomas SM, et al (2018) The clinical significance of breast-only and node-only pathologic complete response (pCR) after neoadjuvant chemotherapy (NACT): a review of 20,000 breast cancer patients in the national cancer data base (NCDB) Ann Surg 268(4) 591-601 https://doi.org/10.1097/SLA.0000000000002953 PMID: 30048319 PMCID: 6496955

9. Cortazar P, Zhang L, and Untch M, et al (2014) Pathological complete response and long-term clinical benefit in breast cancer: the CTNeoBC pooled analysis Lancet 384(9938) 164-172 https://doi.org/10.1016/S0140-6736(13)62422-8 PMID: 24529560

10. Pathologic complete response in neoadjuvant treatment of high-risk early-stage breast cancer: use as an endpoint to support accelerated approval [https://www.fda.gov/regulatory-information/search-fda-guidance-documents/pathologic-complete-response-neoadjuvant-treatment-high-risk-early-stage-breast-cancer-use-endpoint]

11. Masuda N, Lee S-J, and Ohtani S, et al (2017) Adjuvant capecitabine for breast cancer after preoperative chemotherapy N Engl J Med 376(22) 2147-2159 https://doi.org/10.1056/NEJMoa1612645

12. von Minckwitz G, Huang C-S, and Mano MS, et al (2019) Trastuzumab emtansine for residual invasive HER2-positive breast cancer N Engl J Med 380(7) 617-628 https://doi.org/10.1056/NEJMoa1814017

13. Loibl S, O'Shaughnessy J, and Untch M, et al (2018) Addition of the PARP inhibitor veliparib plus carboplatin or carboplatin alone to standard neoadjuvant chemotherapy in triple-negative breast cancer (BrighTNess): a randomised, phase 3 trial Lancet Oncol 19(4) 497-509 https://doi.org/10.1016/S1470-2045(18)30111-6 PMID: 29501363

14. Hurvitz SA, Martin M, and Symmans WF, et al (2018) Neoadjuvant trastuzumab, pertuzumab, and chemotherapy versus trastuzumab emtansine plus pertuzumab in patients with HER2-positive breast cancer (KRISTINE): a randomised, open-label, multicentre, phase 3 trial Lancet Oncol 19(1) 115-126 https://doi.org/10.1016/S1470-2045(17)30716-7

15. Sharma P, López-Tarruella S, and García-Saenz JA, et al (2018) Pathological response and survival in triple-negative breast cancer following neoadjuvant carboplatin plus docetaxel Clin Cancer Res 24(23) 5820-5829 https://doi.org/10.1158/1078-0432.CCR-18-0585 PMID: 30061361 PMCID: 6279513

16. Johnston S, Puhalla S, and Wheatley D, et al (2019) Randomized phase Il study evaluating palbociclib in addition to letrozole as neoadjuvant therapy in estrogen receptor-positive early breast cancer: PALLET trial J Clin Oncol 37(3) 178-189 https://doi.org/10.1200/ JCO.18.01624

17. Nanda R, Liu MC, and Yau C, et al (2020) Effect of pembrolizumab plus neoadjuvant chemotherapy on pathologic complete response in women with early-stage breast cancer: an analysis of the ongoing phase 2 adaptively randomized I-SPY2 trial JAMA Oncol https://doi. org/10.1001/jamaoncol.2019.6650 
18. Schmid P, Salgado R, and Park YH, et al (2020) Pembrolizumab plus chemotherapy as neoadjuvant treatment of high-risk, early-stage triple-negative breast cancer: results from the phase 1b open-label, multicohort KEYNOTE-173 study Ann Oncol 31(5) 569-581 https://doi.org/10.1016/j.annonc.2020.01.072 PMID: 32278621

19. Schmid P, Cortes J, and Pusztai L, et al (2020) Pembrolizumab for early triple-negative breast cancer New Engl J Med 382(9) 810-821 https://doi.org/10.1056/NEJMoa1910549 PMID: 32101663

20. Loibl S, Untch M, and Burchardi N, et al (2019) A randomised phase Il study investigating durvalumab in addition to an anthracycline taxane-based neoadjuvant therapy in early triple-negative breast cancer: clinical results and biomarker analysis of GeparNuevo study Ann Oncol 30(8) 1279-1288 https://doi.org/10.1093/annonc/mdz158 PMID: 31095287

21. Gianni L, Huang CS, and Egle D, Bermejo B, et al (2019) Pathologic complete response (pCR) to neoadjuvant treatment with or without atezolizumab in triple negative, early high-risk and locally advanced breast cancer. NeoTRIPaPDL1 Michelangelo randomized study sabcs: 2019

22. Schmid P, Adams S, and Rugo HS, et al (2018) Atezolizumab and nab-paclitaxel in advanced triple-negative breast cancer N Engl J Med 379(22) 2108-2121 https://doi.org/10.1056/NEJMoa1809615 PMID: 30345906

23. Topalian SL, Taube JM, and Pardoll DM (2020) Neoadjuvant checkpoint blockade for cancer immunotherapy Science 367(6477) eaax0182 https://doi.org/10.1126/science.aax0182 PMID: 32001626

24. Liu J, Blake SJ, and Yong MC, et al (2016) Improved efficacy of neoadjuvant compared to adjuvant immunotherapy to eradicate metastatic disease Cancer Discov 6(12) 1382-1399 https://doi.org/10.1158/2159-8290.CD-16-0577 PMID: 27663893

25. Forde PM, Chaft JE, and Smith KN, et al (2018) Neoadjuvant PD-1 blockade in resectable lung cancer N Engl J Med 378(21) 1976-1986 https://doi.org/10.1056/NEJMoa1716078 PMID: 29658848 PMCID: 6223617

26. Blank CU, Rozeman EA, and Fanchi LF, et al (2018) Neoadjuvant versus adjuvant ipilimumab plus nivolumab in macroscopic stage III melanoma Nat Med 24(11) 1655-1661 https://doi.org/10.1038/s41591-018-0198-0 PMID: 30297911

27. Blank CU, Versluis JM, and Reijers LM, et al (2019) 3-year relapse-free survival (RFS), overall survival (OS) and long-term toxicity of (neo) adjuvant ipilimumab (IPI) + nivolumab (NIVO) in macroscopic stage iii melanoma (OPACIN trial) Ann Oncol 30(5) v533-v563 https://doi. org/10.1093/annonc/mdz255.003

28. Roche provides update on Phase III study of Tecentriq in combination with paclitaxel for people with metastatic triple-negative breast cancer [news release] [https://www.roche.com/media/releases/med-cor-2020-08-06.htm]

29. Ma Y, Mattarollo SR, and Adjemian S, et al (2014) CCL2/CCR2-dependent recruitment of functional antigen-presenting cells into tumors upon chemotherapy. Cancer Res 74(2) 436-445 https://doi.org/10.1158/0008-5472.CAN-13-1265

30. McDonnell AM, Lesterhuis WJ, and Khong A, et al (2015) Tumor-infiltrating dendritic cells exhibit defective cross-presentation of tumor antigens, but is reversed by chemotherapy Eur J Immunol 45(1) 49-59 https://doi.org/10.1002/eji.201444722

31. Nowak AK, Lake RA, and Marzo AL, et al (2003) Induction of tumor cell apoptosis in vivo increases tumor antigen cross-presentation, cross-priming rather than cross-tolerizing host tumor-specific CD8 T cells J Immunol 170(10) 4905-4913 https://doi.org/10.4049/jimmunol.170.10.4905 PMID: 12734333

32. Machiels JP, Reilly RT, and Emens LA, et al (2001) Cyclophosphamide, doxorubicin, and paclitaxel enhance the antitumor immune response of granulocyte/macrophage-colony stimulating factor-secreting whole-cell vaccines in HER-2/neu tolerized mice Cancer Res 61(9) 3689-3697 PMID: 11325840

33. Pfannenstiel LW, Lam SSK, and Emens LA, et al (2010) Paclitaxel enhances early dendritic cell maturation and function through TLR4 signaling in mice Cell Immunol 263(1) 79-87 https://doi.org/10.1016/j.cellimm.2010.03.001 PMID: 20346445 PMCID: 2862830

34. Ghiringhelli F, Menard C, and Puig PE, et al (2007) Metronomic cyclophosphamide regimen selectively depletes CD4+CD25+ regulatory T cells and restores T and NK effector functions in end stage cancer patients. Cancer Immunol Immunother 56(5) 641-648 https:// doi.org/10.1007/s00262-006-0225-8 
35. Voorwerk L, Slagter M, and Horlings HM, et al (2019) Immune induction strategies in metastatic triple-negative breast cancer to enhance the sensitivity to PD-1 blockade: the TONIC trial Nat Med 25(6) 920-928 https://doi.org/10.1038/s41591-019-0432-4 PMID: 31086347

36. Bear HD, Anderson S, and Brown A, et al (2003) The effect on tumor response of adding sequential preoperative docetaxel to preoperative doxorubicin and cyclophosphamide: preliminary results from National Surgical Adjuvant Breast and Bowel Project Protocol B-27 J Clin Oncol 21(22) 4165-4174 https://doi.org/10.1200/JCO.2003.12.005 PMID: 14559892

37. von Minckwitz G, Blohmer JU, and Costa SD, et al (2013) Response-guided neoadjuvant chemotherapy for breast cancer J Clin Oncol 31(29) 3623-3630 https://doi.org/10.1200/JCO.2012.45.0940 PMID: 24002511

38. Mittendorf EA, Zhang $\mathrm{H}$, and Barrios $\mathrm{CH}$, et al (2020) Neoadjuvant atezolizumab in combination with sequential nab-paclitaxel and anthracycline-based chemotherapy versus placebo and chemotherapy in patients with early-stage triple-negative breast cancer (IMpassion031): a randomised, double-blind, phase 3 trial Lancet 396(10257) https://doi.org/10.1016/S0140-6736(20)31953-X PMID: 32966830

39. Loi S, Giobbie-Hurder A, and Gombos A, et al (2019) Pembrolizumab plus trastuzumab in trastuzumab-resistant, advanced, HER2positive breast cancer (PANACEA): a single-arm, multicentre, phase 1b-2 trial Lancet Oncol 20(3) 371-382 https://doi.org/10.1016/ S1470-2045(18)30812-X PMID: 30765258

40. Hegde PS and Chen DS (2020) Top 10 Challenges in Cancer Immunotherapy Immunity 52(1) 17-35 https://doi.org/10.1016/j. immuni.2019.12.011 PMID: 31940268

41. Zaretsky JM, Garcia-Diaz A, and Shin DS, et al (2016) Mutations associated with acquired resistance to PD-1 blockade in melanoma $N$ Engl J Med 375(9) 819-829 https://doi.org/10.1056/NEJMoa1604958 PMID: 27433843 PMCID: 5007206

42. Peng W, Chen JQ, and Liu C, et al (2016) Loss of PTEN promotes resistance to T cell-mediated immunotherapy Cancer Discov 6(2) 202-216 https://doi.org/10.1158/2159-8290.CD-15-0283 PMCID: 4744499

43. Koyama S, Akbay EA, and Li YY, et al (2016) STK11/LKB1 deficiency promotes neutrophil recruitment and proinflammatory cytokine production to suppress T-cell activity in the lung tumor microenvironment Cancer Res 76(5) 999-1008 https://doi.org/10.1158/00085472.CAN-15-1439 PMID: 26833127 PMCID: 4775354

44. Le DT, Uram JN, Wang H, and Bartlett BR, et al (2015) PD-1 blockade in tumors with mismatch-repair deficiency N Engl J Med 372(26) 2509-2520 https://doi.org/10.1056/NEJMoa1500596 PMID: 26028255 PMCID: 4481136

45. Garon EB, Rizvi NA, and Hui R, et al (2015) Pembrolizumab for the treatment of non-small-cell lung cancer N Engl J Med 372(21) 20182028 https://doi.org/10.1056/NEJMoa1501824 PMID: 25891174

46. Schmid P, Park YH, and Ferreira M, et al (2019) KEYNOTE-522 study of neoadjuvant pembrolizumab + chemotherapy vs placebo + chemotherapy, followed by adjuvant pembrolizumab vs placebo for early triple-negative breast cancer: pathologic complete response in key subgroups and by treatment exposure, residual cancer burden, and breast-conserving surgery SABCS: 2019

47. Cortes J, Cescon DW, and Rugo HS, et al (2020) KEYNOTE-355: Randomized, double-blind, phase III study of pembrolizumab + chemotherapy versus placebo + chemotherapy for previously untreated locally recurrent inoperable or metastatic triple-negative breast cancer J Clin Oncol 38(15_suppl) 1000 https://doi.org/10.1200/JCO.2020.38.15_suppl.1000

48. Denkert C, von Minckwitz G, and Darb-Esfahani S, et al (2018) Tumour-infiltrating lymphocytes and prognosis in different subtypes of breast cancer: a pooled analysis of 3771 patients treated with neoadjuvant therapy Lancet Oncol 19(1) 40-50 https://doi.org/10.1016/ S1470-2045(17)30904-X

49. Solinas C, Ceppi M, and Lambertini M, et al (2017) Tumor-infiltrating lymphocytes in patients with HER2-positive breast cancer treated with neoadjuvant chemotherapy plus trastuzumab, lapatinib or their combination: a meta-analysis of randomized controlled trials Cancer Treat Rev 57 8-15 https://doi.org/10.1016/j.ctrv.2017.04.005 PMID: 28525810 
50. Adams S, Goldstein LJ, and Sparano JA, et al (2015) Tumor infiltrating lymphocytes (TILs) improve prognosis in patients with triple negative breast cancer (TNBC) Oncoimmunology 4(9) e985930-e985930 https://doi.org/10.4161/2162402X.2014.985930 PMID: 26405612 PMCID: 4570112

51. Gonzalez-Ericsson P, Sanchez V, and Salgado R (2019) The immune landscape of residual triple-negative breast cancers after neoadjuvant chemotherapy SABCS 2019: 2019

52. Mori H, Kubo M, and Kai M, et al (2019) T-bet(+) lymphocytes infiltration as an independent better prognostic indicator for triple-negative breast cancer Breast Cancer Res Treat 176(3) 569-577 https://doi.org/10.1007/s10549-019-05256-2 PMID: 31069590 PMCID: $\underline{6586701}$

53. Kotoula V, Chatzopoulos K, and Lakis S, et al (2016) Tumors with high-density tumor infiltrating lymphocytes constitute a favorable entity in breast cancer: a pooled analysis of four prospective adjuvant trials Oncotarget 7(4) 5074-5087 https://doi.org/10.18632/ oncotarget.6231 PMCID: 4826267

54. Ignatiadis M, Singhal SK, and Desmedt C (2012) Gene modules and response to neoadjuvant chemotherapy in breast cancer subtypes: a pooled analysis J Clin Oncol 30(16) 1996-2004 https://doi.org/10.1200/JCO.2011.39.5624 PMID: 22508827

55. Ignatiadis M, Van den Eynden G, and Roberto S, et al (2018) Tumor-infiltrating lymphocytes in patients receiving trastuzumab/pertuzumab-based chemotherapy: a TRYPHAENA substudy JNCI 111(1) 69-77 https://doi.org/10.1093/jnci/djy076 PMID: 29788230 PMCID: 6335115

56. Goel S, DeCristo MJ, and Watt AC, et al (2017) CDK4/6 inhibition triggers anti-tumour immunity Nature 548(7668) 471-475 https:// doi.org/10.1038/nature23465 PMID: 28813415 PMCID: 5570667

57. Deng J, Wang ES, and Jenkins RW, et al (2018) CDK4/6 inhibition augments antitumor immunity by enhancing T-cell activation Cancer Discov 8(2) 216-233 https://doi.org/10.1158/2159-8290.CD-17-0915 PMCID: 5809273

58. Teo ZL, Versaci S, and Dushyanthen S, et al (2017) Combined CDK4/6 and PI3Ka inhibition is synergistic and immunogenic in triplenegative breast cancer Cancer Res 77(22) 6340-6352 https://doi.org/10.1158/0008-5472.CAN-17-2210 PMID: 28947417

59. McArthur HL, Diab A, and Page DB, et al (2019) A pilot study of preoperative single-dose ipilimumab and/or cryoablation in women with early-stage breast cancer with comprehensive immune profiling Clin Cancer Res 22(23) 5729-5737 https://doi.org/10.1158/10780432.CCR-16-0190

60. Ko EC and Formenti SC (2019) Radiation therapy to enhance tumor immunotherapy: a novel application for an established modality Int J Radiat Biol 95(7) 936-939 https://doi.org/10.1080/09553002.2019.1623429 PMID: 31120369

61. Hammami A, Allard D, and Allard B, et al (2019) Targeting the adenosine pathway for cancer immunotherapy Semin Immunol 42 101304101304 https://doi.org/10.1016/j.smim.2019.101304 PMID: 31604539 